\title{
Exposure of Mouse Peritoneal Resident Macrophages to Pristine MWCNT Promote Nitric Oxide Synthase Production and Acute Cytokine Response
}

\author{
Flaviu TABARAN ${ }^{1,2 *}$, Teodora MOCAN ${ }^{2}$, Lucian MOCAN ${ }^{2}$, Cristian T. MATEA ${ }^{2}$ \\ Andras NAGY ${ }^{1}$, Marian TAULESCU ${ }^{1}$, Adrian Florin Gal ${ }^{1}$, Cornel CĂTOI ${ }^{1}$ \\ ${ }^{1}$ Department of Anatomic Pathology, University of Agricultural Sciences and Veterinary Medicine Cluj- \\ Napoca, Romania, ${ }^{2}$ Regional Institute of Gastroenterology and HepatologyProf.Dr. "O. Fodor", Cluj- \\ Napoca, Romania \\ *Corresponding author e-mail: alexandru.tabaran@usamvcluj.ro
}

Bulletin UASVM Veterinary Medicine 71(2) / 2014,

Print ISSN 1843-5270; Electronic ISSN 1843-5378

DOI:10.15835/buasvmcn-vm: 10866

\begin{abstract}
Thepotentialbiomedical applicationsof carbon nanotubesare greatlylimited due to thegrowing evidences of their toxic effects on consumers. Recently, the cells of the monocyte-macrophage-system were observed to be the main structures of accumulation and toxicity of these nanomaterials.This study aimed to determine the changes in the inflammatory status and apoptosissuffered by macrophages following exposure to pristine multi-walled carbon nanotubes (MWCNT). Macrophages were isolated from the mouse peritoneum and cultivated in vitro following a protocol previously described by Zhang et al.(2008). The immunocytochemicalexpression of iNOs, IL-6 and apoptosis was measured by fluorometry usingConfocal laser scanning microscopy (CLSM).

Exposure of peritoneal macrophages to MWCNT promotesiNOs production and IL-6 expression in a doserelated matter. The exposure to 10 and $25 \mu \mathrm{g} / \mathrm{dl}$ MWCNTdoes not induce apoptosis in macrophage culture, although a significant increase in numbers of cellsundergoing apoptosis is observed for the group exposed at $50 \mu \mathrm{g} / \mathrm{dl}$ MWCNT. In the present research we demonstrated that exposure of mouse macrophages to pristine MWCNTpromote nitric oxide synthase production and an acute cytokine responsecharacterized by the elevation of IL-6 levels. Apoptosis is increased only at high levels of MWCNT exposure, being in respect of our results, a late expression of toxicity.
\end{abstract}

Keywords: carbon nanotubes, inflammation, peritoneal macrophages

\section{INTRODUCTION}

Carbon nanotubes (CNT) are nanoscale cylindrical graphene sheets from the fullerene family being discovered by Iijima Japanese scientist in the early nineties. Since then, due to extraordinary proprieties, remarkable work was made in the implementation of these new generation materials in various fields, from basic material science to nanomedicine. This increasing production and the widespread application of these nanomaterials provides multiple sources of contamination for humans, thereby raising concern about the interaction between nanomaterials and living beings mainly about the risk that these materials have on humans This concern is maintained by the conflicting conclusions of the toxicological studies, results which are difficult to be grouped under a single, definitive conclusion. Thus, the toxicological results varies between studies from mesotheliomas (Poland, 2008) and acute lethality following airborne exposure (ChiuWing, 2004) to the lack of any changes in the body that could indicate toxicity (Kam 2005).

Nevertheless, one of the main ideas which are constantly validated in the pristine carbon nanotube toxicology reports are their accumulation in the cells of the monocyte-macrophage system (MM), mainly in fixed macrophages, the main 
active-phagocytic cells of the system (Muller 2005, Deng 2007). We also observed that after systemic administration, CNT in their single-walled or multiwalled have a strong tropism for the macrophages, this nanoparticle biodistribution being intimately linked with the presence of phagocytic-active macrophages.

Macrophages are highly dynamic cells with a key role in both innate (mainly by the phagocyticactivity) and acquired defence processes. Afterbirthmacrophage has beside the phagocytic function and initialization of the inflammatory process also a secretory role for the coagulation factors and complement component (Ringler 1997, Lewis 2006).

\section{MATERIALS AND METHODS}

Carbon Nanotubes; Short multi-wall carbonnanotubes (MWCNT) were purchased fromSigma-Aldricht (product code 636495), the standard carbonaceous materialbeing produced by Chemical vapor deposition (CVD) method. The assessed purity of the material was $>95 \%$, the length range between 0.5 and $2 \mu \mathrm{m}$ (short MWCNT), theOutside Diameter 20-30 nm and the wall thickness (carbon sheet thickness ) ranging between 1 and $2 \mathrm{~nm}$.

\section{Suspension and dispersion of MWCNT}

Sincecarbonnanotubes arehighly hydrophobic and in biological environment tend to form micron-sized bulks that will largely interfere with the experiment results, for a properassessment of their interaction at the nano-scale with living cells the carbonaceous material was suspended in cell cultured medium (in our case RPMI media) enriched with Dimethyl sulfoxide (DMSO) (the final concentration of the DMSO in cell medium was $0,5 \%$ ) and repeatedlyultrasonicated, following the protocol previously described by Asakura et al. (2010).

\section{Mouse Resident Peritoneal Macrophages Isolation and Culture}

Adult pathogen-free male Swiss mice weighing between 28 and $42 \mathrm{~g}$ were kept in individual ventilated cages at $22-25^{\circ} \mathrm{C}, 40-50$ humidity, and 12:12 light/dark cycle. Animals were allowed ad libitum water and standard mouse chow.

Peritoneal macrophages $(\mathrm{M} \varphi)$ were recovered from the mice peritoneal cavity following a protocol previously described by Kim et al.(1997) and Zhang et al.(2008), optimized for our laboratory conditions. Briefly, immediately followingeuthanasiaand abdomen asepsis with $70 \%$ isopropyl alcohol, $10 \mathrm{ml}$ of ice cold, sterile, calcium and magnesium cloride freeDulbecco's Phosphate Buffered Saline (DPBS)(Sigma-Aldricht, product code D8537) was gently injected in the caudal-right quadrate of the abdominal cavity. After 20 seconds of softly massage of the abdomen, the medium was recovered and centrifuged at $1500 \mathrm{rpm}$ for $5 \mathrm{~min}$. The cell pallet was suspended in RPMI-1640 Medium (Sigma-Aldricht, product code R8758) and brought at an optimal number of $2 \times 10^{6}$ cells/mL.For an appropriate purity, the cells were assetby immunocytochemistry for macrosialin and Mac1 beta chain. After 3 hours of incubation the cells were repeatedly washed to remove non-adherent cells (mainly $\mathrm{B}$ and $\mathrm{T}$ cells) and incubate with fresh RPMI-1640 Medium enriched with 10\% FBS and 1\% streptomycin/ gentamicine overnight.

\section{Exposure of Mouse Resident Peritoneal Macrophages to MWCNT}

Peritoneal macrophage cultures were exposedfor 7 hoursat 10, 20 and $50 \mu \mathrm{g} / \mathrm{dl}$ MWCNTin RPMI medium.

\section{Light microscopy images}

The cells were analyzed by contrast phase and after Wright-Giemsa stain on an Olympus BX 51 microscope, and images were taken using the

Table 1. Description of the antibodies used in this study

\begin{tabular}{ccccc}
\hline Antibody & Clonality/Isotype & Manufacturer & Code & Dilution \\
\hline iNOs & Polyclonal/IgG & Abcam & ab15323 & $1 / 500$ \\
IL6 & Polyclonal/IgG & Abcam & ab6672 & $1 / 700$ \\
Caspase-3 & Polyclonal/IgG & ThermoScientific & PAK0488 & $1 / 500$ \\
$\begin{array}{c}\text { Goat Anti-Rabbit } \\
\text { (FITC conjugated) }\end{array}$ & Polyclonal/IgG & Abcam & ab6717 & $1 / 5000$ \\
\hline
\end{tabular}


Olympus SP 350 and processed with Olympus stream basic soft.

\section{Immunocytochemistry}

For the assessment of the cell response to MWCNT exposure we used the immunohistochemical expression of inducible Nitric oxide synthase (iNOs) and IL6. The antibody source and dilution can be consulted in table 1 .

Briefly, following exposure the media containing RPMI and MWCNt was repetitively washed with PBS and cells were fixed with icecold acetone for 7 minutes. Primary antibody incubation was conducted at $4^{\circ} \mathrm{C}$ overnight, and the secondary fluorescein isothiocyanate (FITC) conjugated antibodies for $30 \mathrm{~min}$. at room temperature. In the end of the staining process, the cells nuclei were stained with blue pseudocolor (Draq5, Cell Signaling Technology, code 4084) and mounted with a water-compatible medium (Mowiol 4-88, Carl Roth, nr. 0713).

Confocal Scanning Laser Microscopy (CSLM) assessment of cell cultures

Immunofluorescent staining results were observed and quantifiedof cell fluorescence we used an Zeiss LSM-7 mounded on a AxioVision inverted microscope. For the detection of the fluorocromes we used the $495 \mathrm{~nm}$ laser line for FITC and $543 \mathrm{~nm}$ laser line for Draq5. For the entire length of the experiment the capacity of both Argon and HeNe laser was kept at $5 \%$ of their potential.

Quantification of iNOS and IL6 expressions

FITC signal measurement (the fluorescent label for iNOS and IL6) was carried by metaanalysis on the acquired LSM images using the point-by-point fluorescence quantification functions of the ZEN CLSM softwareprovided by Zeiss.

At least different 20 microscopic fields of arbitrary chosen regions were obtained for each group using an 63x oil apochromatic objective. For constant quantification conditions, identical scan speed, output power of the lasers, masterand digital gain were used for all scans.

Each microscopic field was scanned on the in $\mathrm{x}, \mathrm{y}$ and $\mathrm{z}$ axis, resulting an scan volume of 182120 $\mu \mathrm{m}^{3} /$ field. Based on the image quality and cell surface contained for each field was chosen a representative image which was furfure used for quantification.

\section{Quantification of apoptotic cells}

Caspase 3 positive cells were counted in ten, randomly chosen, high power fields (obx63), being reported at the total number of nuclei presented in the analyzed.

\section{Statistical analysis of results}

Measurements were compared using ANOVA statistical system on the Origin 8.5 software. The level of statistical significance set at $p$ value $<0.05$.

\section{RESULTS AND DISCUSSIONS}

Immunocytochemical expression of peritoneal macrophages for iNOS suffers significant changes following exposure to different doses of MWCNT, thus, a significant increase in the expression of iNOS are observed following exposure at concentrations of 10 and $25 \mu \mathrm{g} / \mathrm{dl} \mathrm{dl}$ MWCNT. But even if both values are significantly different from the control, these changes are not observed by comparing the two groups between them. The highest values of iNOS expression is observed in the group exposed to $50 \mu \mathrm{g} / \mathrm{dl}$ MWCNT, were significantly different both the control group and the groups exposed to 10 and $25 \mu \mathrm{g} / \mathrm{dl}$ MWCNT.

Immunocytochemical expression of peritoneal macrophages for IL6 undergoes significant changes following exposure to doses of MWCNT comparing with the control group. This change is observed for all the groups, but important changes in IL6 expression is observed especially for the cells exposed at 25 and $50 \mu \mathrm{g} / \mathrm{dl}$ MWCNT. Interestingly, regarding the differences between the last two groups, no statistical relevant changes are observed between them.

Following the exposure to 10 and $25 \mu \mathrm{g} / \mathrm{dl}$ MWCNT , the number of caspase 3 positive cells suffers no significantchanges comparing with the control group. For macrophage cultures exposed to $50 \mu \mathrm{g} / \mathrm{dl} . M W C N T$ there is a significant increase in cell apoptosis, this increment being observed by cooperation with control groups and also with those expose at 10 and $25 \mu \mathrm{g} / \mathrm{dl}$ MWCNT.

Studies carried out by $\mathrm{He}$ et al. (2011) indicates that the main source of CNT toxicity is the local increment of oxidative stress and afterward the induction of pro-fibrogenic cytokines (mainly IL-1 $\beta$, IL-6, IL-10 and MCP-1). This production of inflammatory cytokines occurs mainly in the local macrophages, resulting in a chronicinflammatory response and induction of fibroblast/myofibroblast proliferation. This is a critical step in CNT 


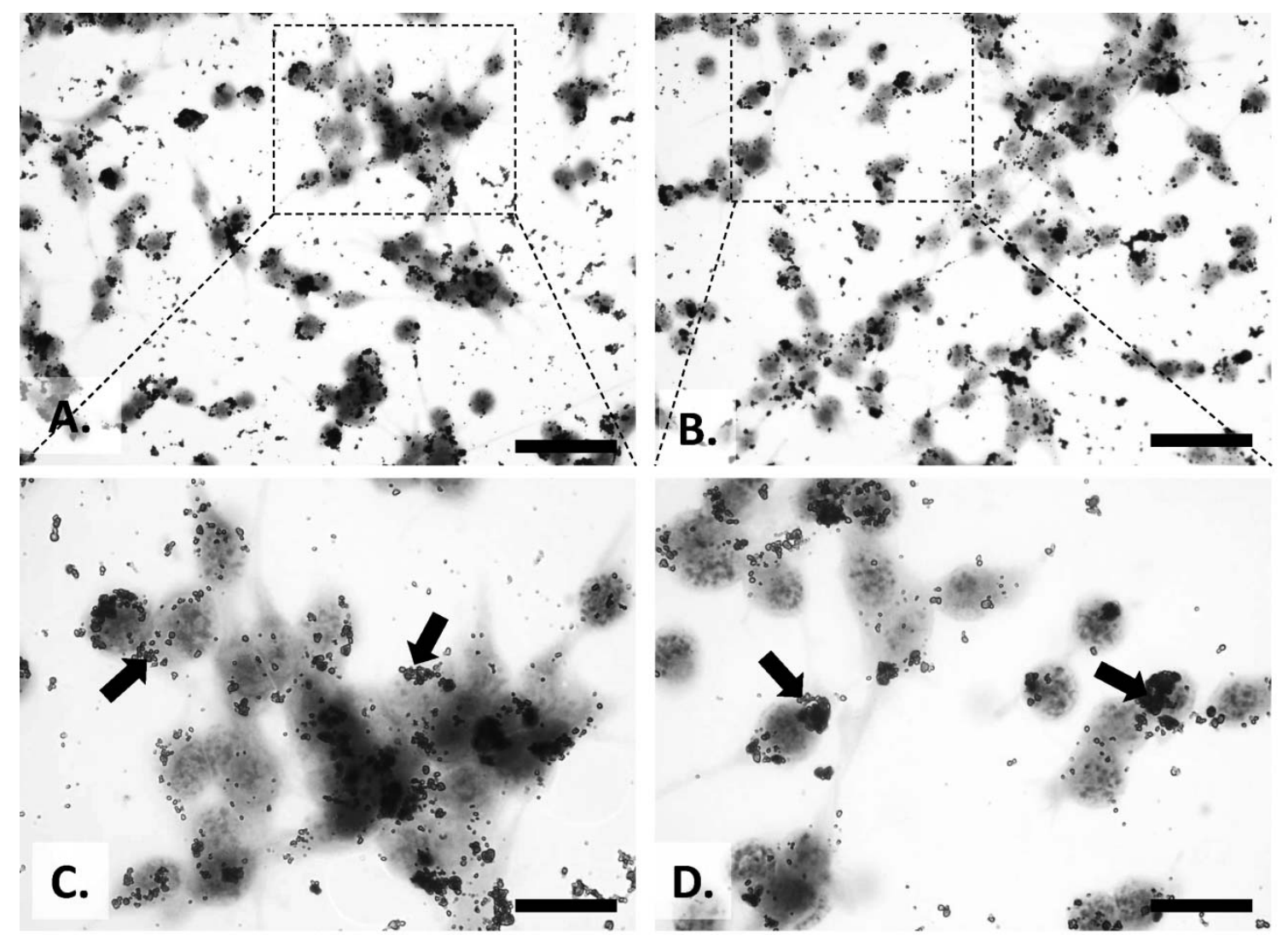

Fig. 1. Mouse peritoneal macrophages exposed to $50 \mu \mathrm{g} / \mathrm{dl}$ MWCNT. Intracellular accumulations of CNT can be observed as brown-black material. Image A and B were acquired using an 40x objective, C and D using an 100x immersion objective. Scale bar represents $100 \mu \mathrm{m}$ for images A and $\mathrm{B}$, respectively $50 \mu \mathrm{m}$ for images $\mathrm{C}$ and D. Wright-Giemsa stain.
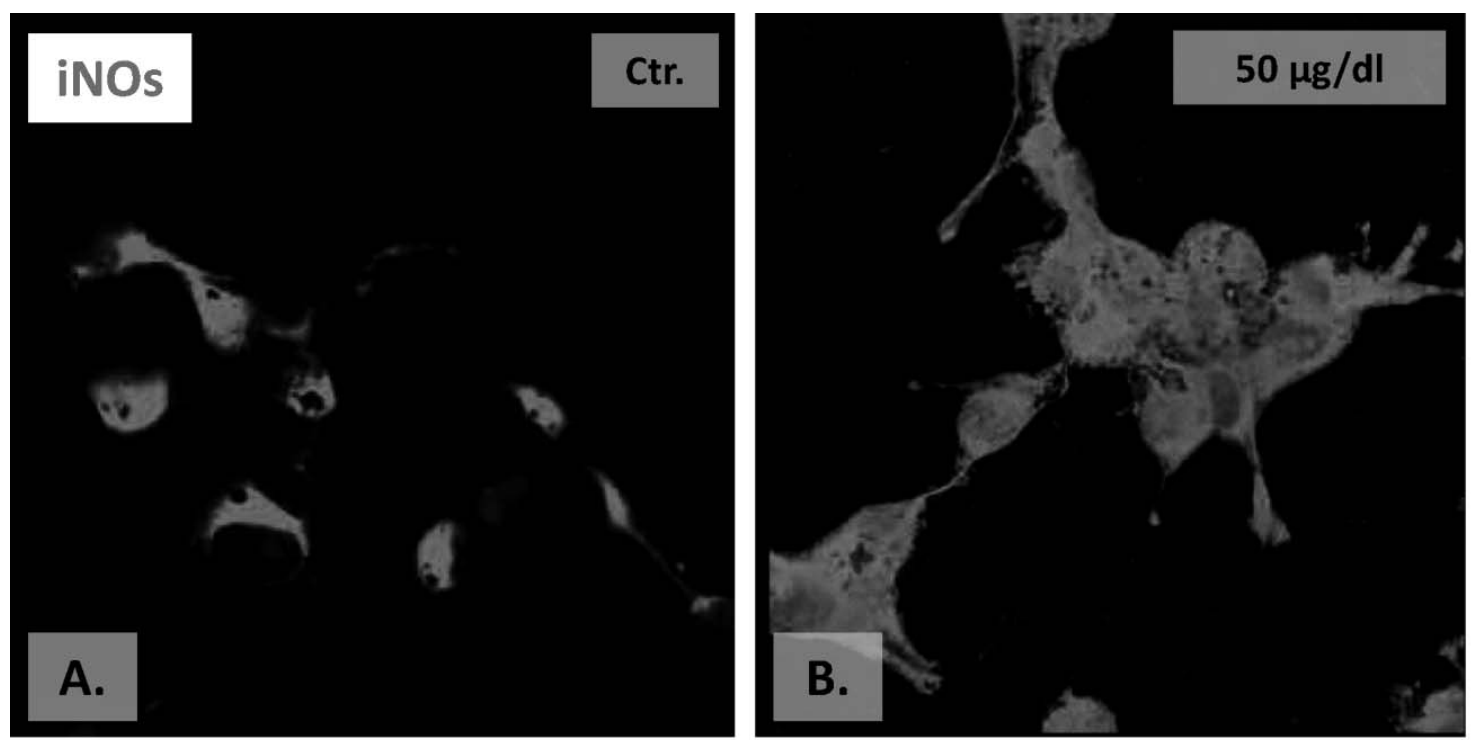

Fig. 2. Immunocytochemical expression of mouse peritoneal macrophages for iNOs. Image a represents the control cells exposed to normal culture medium. Image B represents the cells exposed at $50 \mu \mathrm{g} / \mathrm{dl}$ MWCNT. Ob x63 
toxicity, the local fibroblast/myofibroblast activation being based on the paracrineeffect of the profibrogenic cytokines. This activation of fibroblast and myofibroblast is the basis of the strong deposition of connective fibers (fibroplasia) observed in many nanotoxicologic studies carried out to elucidate the CNT (Lin 2012, Donaldson 2013).

For a better understanding of those expose above, after exposure to nanomaterials, under important elevation in the cell oxidative stress (stages I or II on the scale proposed by Meng et al.) (2009), the macrophages will initiate the expression of proinflammatory cytokines (TGF $\beta$, IL-1, TNF- $\alpha$, etc.). These local molecules will activate the local response granulomatous response or fibroplasia.

The iNOs and IL6 expression is critical for the macrophage function also from another consideration. This cytokine is one of the most important stimuli for the transformation of macrophages from the M1form ("inflammatory macrophage") into the M2 state ("reparatory macrophage") (Mantovani 2007), the last state of activity being importantly involved in local tumor progression (Mantovani 2002).
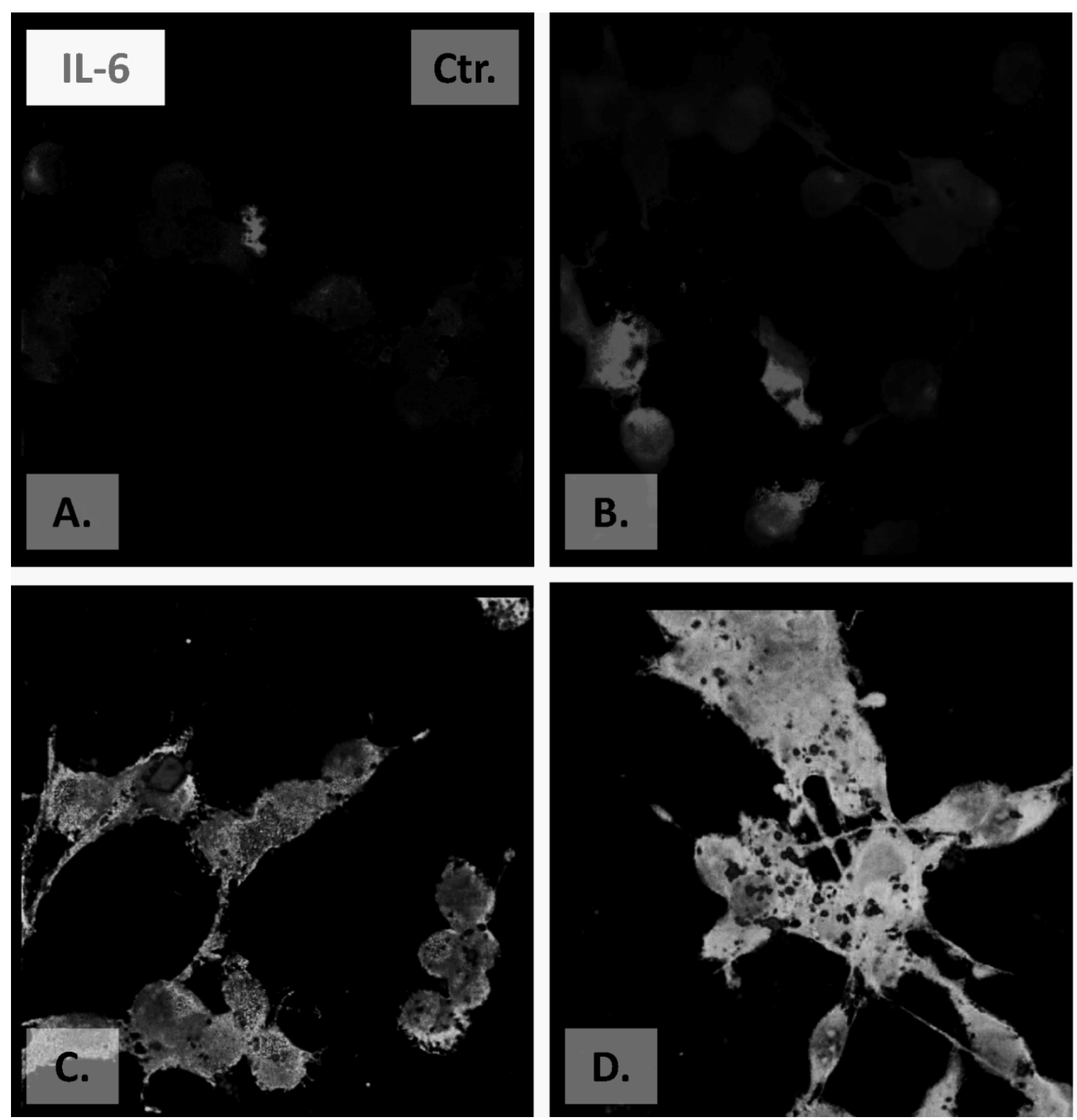

Fig. 3. Immunocytochemical expression of mouse peritoneal macrophages for IL-6. Image A represents the control cells exposed to normal culture medium. Image B, C and D represents the cells exposed at 10, 25 and $50 \mu \mathrm{g} / \mathrm{dl}$ MWCNT. Ob x63 


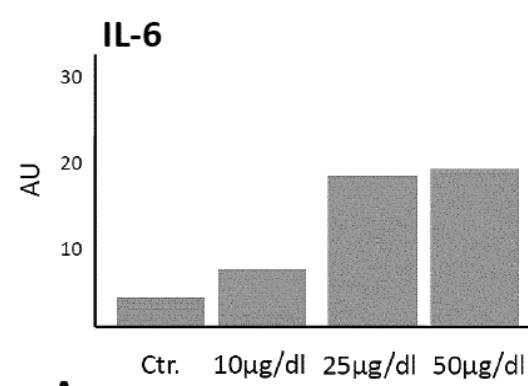

A.

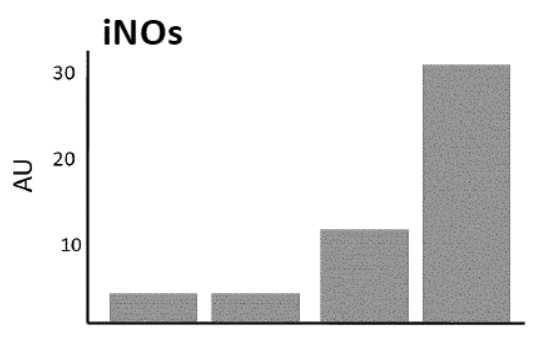

B.

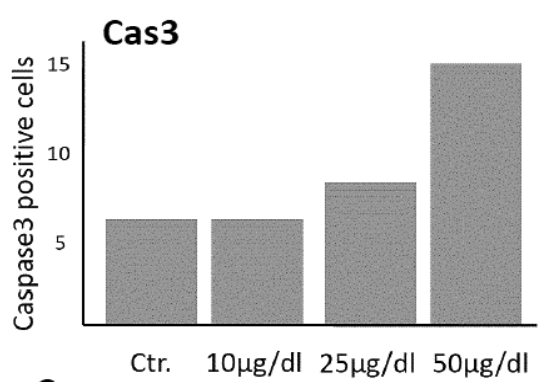

C.

Fig. 4. Immunocytochemical expression of IL-6 -A, iNOs-B and median number of apoptotic cells -C

In nanomaterial toxicology the oxidative stress and inflammation are closely related and interrelated processes, being difficult to distinguish the initial and the most intensive process due to the vicious circle in which the: oxidative stress induces inflammation which, in turn produces oxidizing factors that maintain systemic and local (cellular) oxidative stress.

In addition to the mechanism of oxidative stress as an inductor of inflammationfollowing CNT exposure, this inflammatory reaction can be due to direct influence of the internalizedparticles on cell organelles (Brown 2007). Incomplete capture of carbon nanotubes can lead to erratic coupling of lysosomes with early endosomes and in the outpouring of the lysosomeenzymes into the cytosol or extracellular. This mode is one of most important associated phenomenon of incomplete phagocytosis (or "frustrated phagocytosis") which appears secondary to incomplete internalization of long particle, this mechanism being wellcharacterized for particles such as asbestos (Cheng 2009, Ali-Boucetta 2013).

Partially, the inflammatory molecules expressed by macrophages consecutive to the exposure to CNT will action also as paracrine stimuli for other immune cells, as $\mathrm{T}$ and $\mathrm{B}$ cells or local Dendritic cells. This mechanism is the main way by which nanomaterials can boost the immune system response (Hussain 2012, Zhou 2014), this mechanism being speculated today more and more for the immunoprevention an immunotheraphy in critical fields as oncology (Battigelli 2014).

\section{CONCLUSION}

In this study we demonstrated that exposure of mouse peritoneal macrophages to pristine MWCNT promote nitric oxide synthase production and an cytokine responsecharacterized by the elevation of IL-6 levels. Apoptosis is increased only at high levels of MWCNT exposure, being in respect of our results, a late expression of toxicity.

\section{Acknowledgements}

The research was conducted with the support of Unitatea Executivă pentru Finanțarea Învățământului Superior, a Cercetării, Dezvoltării și Inovării grant PN-II-PT-PCCA-76/2012 (VACCINAN).

Dr. Flaviu Tabaran, Teodora Mocan, Lucian Mocan,Cristian T. Matea, Andras Nagy, Marian Taulescu acknowledges financial support from an POSDRU grant, no. 159/1.5/S/136893 grant with title: "Parteneriat strategic pentrucreștereacalităț iicercetăriiștiințifice din universitățilemedicalepri nacordarea de burse doctorale și postdoctorale DocMed.Net_2.0"

\section{REFERENCES}

1. Ali-Boucetta H, Nunes A, Sainz R, Herrero MA, Tian B, Prato M, Kostarelos K(2013). Asbestos-like Pathogenicity of Long Carbon Nanotubes Alleviated by Chemical Functionalization. AngewandteChemie, 125(8):23302334.

2. Asakura M, Sasaki T, Sugiyama T, Takaya M, Koda S, Nagano K, Fukushima S (2010). Genotoxicity and cytotoxicity of multi-wall carbon nanotubes in cultured Chinese hamster lung cells in comparison with chrysotileA fibers. Journal of occupational health 52(3): 155-166.

3. Battigelli A, Ménard-Moyon C, Bianco A (2014). Carbon nanomaterials as new tools for immunotherapeutic applications. Journal of Materials Chemistry B2(37): 6144-6156.

4. Brown DM, Kinloch IA, Bangert U, Windle AH, Walter DM, Walker GS, Stone V (2007). An in vitro study of the potential of carbon nanotubes and nanofibres to induce inflammatory mediators and frustrated phagocytosis. Carbon 45(9): 1743-1756.

5. Cheng C, Müller KH, Koziol KK, Skepper JN, Midgley PA, Welland ME, Porter AE (2009). Toxicity and imaging of 
multi-walled carbon nanotubes in human macrophage cells. Biomaterials, 30(25): 4152-4160.

6. Chiu-Wing L, James T, Mccluskey R, Hunter L (2004). Pulmonary Toxicity of Single-Wall Carbon Nanotubes In Mice 7 And 90 Days After Intratracheal Instillation, Toxicological Sciences 77: 126-134.

7. Deng X, Jia G, Wang H, Sun H, Wang X, Yang S, Liu Y (2007). Translocation and fate of multi-walled carbon nanotubes in vivo. Carbon, 45(7): 1419-1424.

8. Donaldson K, Poland CA, Murphy FA, MacFarlane M, Chernova T, Schinwald A (2013). Pulmonary toxicity of carbon nanotubes and asbestos-similarities and differences. Advanced drug delivery reviews 65(15): 2078-2086.

9. HeX, Young H, Fernback J, Ma Q(2011).Multiwalled carbon nanotubes induce a fibrogenic response by stimulating reactive oxygen species production, activating NF- $\kappa \mathrm{B}$ signaling, and promoting fibroblast-to-myofibroblast transformation, Nanotoxicology24:(12): 2237-2248.

10. Hussain S, JeroenA, Vanoirbeek J, Peter H, Hoet M (2012). Interactions of nanomaterials with the immune system, WIREs NanomedNanobiotechnol 4: 169-183.

11. Kam NW, O'Connell M, Wisdom J, Dai H(2005). Carbon nanotubes as multifunctional biological transporters and near-infrared agents for selective cancer cell destruction, ProcNatlAcadSci U S A 102:23: 11600-11605.

12. Kim JG, KeshavaC, Murphy AA, Pitas RE, Parthasarathy $S$ (1997). Fresh mouse peritoneal macrophages have low scavenger receptor activity.Journal of lipid research, 38(11) 2207-2215.

13. Lee JK, Sayers BC, Chun KS, Lao HC, Shipley-Phillips JK, Bonner JC, Langenbach R (2012). Multi-walled carbon nanotubes induce COX-2 and iNOS expression via MAP Kinase-dependent and-independent mechanisms in mouse RAW264. 7 macrophages. Part FibreToxicol(9): 14.

14. Lewis CE, Pollard JW (2006). Distinct role of macrophages in different tumor microenvironments. Cancer Res. 66(2):605-612.

15. Lin Z, Liu L, Xi Z, Huang J, Lin B(2012). Single-walled carbon nanotubes promote rat vascular adventitial fibroblasts to transform into myofibroblasts by SM22- $\alpha$ expression. International journal of nanomedicine7: 4199.

16. Mantovani A,Sica A, Locati M (2007). New vistas on macrophage differentiation and activation. European journal of immunology 37(1): 14-16.

17. Mantovani A, Sozzani S, Locati M, Allavena P, Sica A (2002). Macrophage polarization: tumor-associated macrophages as a paradigm for polarized M2 mononuclear phagocytes. Trends in immunology, 23(11): 549-555.

18. Meng H, Xia T, Saji G, NelAE(2009). A Predictive Toxicological Paradigm for the Safety Assessment of Nanomaterials, ACS Nano 3(7):1620-1627.

19. Muller J, Huaux F, Moreau N, Misson P, Heilier JF, Delos M, Lison D (2005). Respiratory toxicity of multi-wall carbon nanotubes. Toxicology and applied pharmacology 207(3): 221-231.

20. Poland CA, Duffin R, Kinloch I, Maynard A, Wallace WA, Seaton A, Donaldson K (2008). Carbon nanotubes introduced into the abdominal cavity of mice show asbestos-like pathogenicity in a pilot study. Nature nanotechnology 3(7): 423-428.

21. Ringler DJ (1997) "Inflammation and repair" in Veterinary Pathology (6th edition), Williams and Wilkins, Baltimore, Jones TC, RD Hunt, King NW, 113-159.

22. Tăbăran AF, Catoi C (2014). Macrophages Targeted Drug Delivery as a Key Therapy in Infectious Disease, Biotechnology, Molecular Biology and Nanomedicine 02:1:2330-9318.

23. Tabaran $F(2010)$. The Biodistribution And Acute Systemic toxicity of Single Walled Carbon -Nanotube Functionalized With Single-Strand DNA In Wistar Rats, Journal of Comparative Pathology 143: (4): 316.

24. Zhang X, Goncalves R, Mosser D M (2008). The isolation and characterization of murine macrophages. Current protocols in immunology 14-1.

25. Zhou S, Hashida Y, Kawakami S, Mihara J, Umeyama T, Imahori H, Hashida M (2014). Preparation of immunostimulatory single-walled carbon nanotube/CpG DNA complexes and evaluation of their potential in cancer immunotherapy. International journal of pharmaceutics. 